\title{
6
}

\section{Making Room for Magic in Intellectual Property Policy}

\author{
Miranda Forsyth
}

\section{Miranda Forsyth: Personal Journey}

I first went to Vanuatu in 2001 as a volunteer legal officer and worked in the Office of the Public Prosecutor for a year. During this time, I became fascinated with the non-state system of justice (kastom), with its emphasis on dialogue and relationships, and the way in which it interacted with the state criminal justice system. After returning to Melbourne, I successfully applied for a position at the School of Law at the University of the South Pacific (USP) and returned to Vanuatu as soon as I could to take up the position. It was a fantastically vibrant time at the School of Law, with considerable interest in bringing the state and non-state justice systems in the region meaningfully into the curriculum as much as possible. This was helped by the enormous work that went into establishing and running Pacific Islands Legal Information Institute (PacLII), the Pacific electronic database for case law and legislation, housed at the Emalus campus of USP in Port Vila.

During my time at USP, I pursued my $\mathrm{PhD}$ in law as a distance student through The Australian National University (ANU). My subject was the relationship between the kastom and state justice systems in Vanuatu and I did my fieldwork around Vanuatu during semester breaks. As a lecturer, I learnt an incredible amount from the students and their insights into how law operated in practice in the region and its complex entanglement with custom and Christianity. I thoroughly enjoyed the challenge of teaching across multiple jurisdictions and learning with the students about the similarities and differences to approaches to legal questions across the region. 
In 2010, I returned to Australia to take up a research-intensive position at ANU where I have continued to work on issues of legal pluralism and retain my strong connection with both the region and USP. In 2019, to my great delight, a student whom I taught in his first year at USP became my PhD student here at ANU.

Forsyth, M. 2015. Making Room for Magic in Intellectual Property Policy. In P. Drahos, G. Ghidini and H. Ullrich (eds), Kritika: Essays on Intellectual Property. Cheltenham: Edward Elgar, 1:84-113

Republished with the kind permission of Edward Elgar Publishing Limited.

\section{Introduction}

Although the global intellectual property regime ${ }^{1}$ is often positioned as being the only intellectual property regime across the globe, there are currently many different regimes regulating the production of, and access to, a range of intangible resources. These alternative intellectual property regimes - such as customary systems, informal contracts, trade secrets and other informal normative systems - are often highly relational and deeply embedded in the social, cultural and political matrix of the group they regulate. Today many of these systems operate in pockets where the global intellectual property system has not as yet spread, but these areas are quickly diminishing as the global system continues to colonise both new geographical regions and also new types of subject matter.

This paper argues that local knowledge and innovation systems are often rendered invisible by the dominance of the global intellectual property system. This is largely due to the state-centric, positivistic paradigm within which the global system, and the institutions that manage it, operate. This in turn means that when new types of intangible resources or innovation start to be recognised as valuable by the global North, such as traditional knowledge, there is a tendency to fail to see the existing regulatory structures that surround them as these structures rarely operate at the level of the state. This type of myopia has been referred to as the 'blank slate fallacy' (Twining 2009:285-86) by legal pluralists who reveal a repeated pattern of marginalisation of non-state regulatory

1 The term global intellectual property regime is used to refer to the international regulatory system established by the Agreement on Trade Related Aspects of Intellectual Property (TRIPS) and subsequently supplemented by a range of multilateral intellectual property agreements. 
orders by state-based legal systems (see, for example, Griffiths 1986; von Benda-Beckmann 1985:187). As a result, the global intellectual property system often colonises these 'new' regulatory spaces through imposing transplanted regulatory regimes. The existing systems are often changed in fundamental ways as a result of the new rules, ideologies and categories of winners and losers, introduced by the new system.

This paper explores these issues through a discussion of the role of magic or spirits in Melanesian intellectual property systems, first identifying their importance in local intellectual property systems and then asking what happens when this dimension is left out by the introduction and dominance of the global intellectual property system. We see how the global system approaches the regulatory challenge of protecting traditional knowledge by separating the 'object' of protection (traditional knowledge) from the system that formed the necessary environment for its production. I then discuss two problematic consequences of failing to take local intellectual property systems into account when extending the global intellectual property regime into new areas. First, the creation of new forms of property rights is likely to interfere with the existing systems in potentially corrosive ways. This is linked in part to what Drahos has referred to as the 'tragedy of commodification' (Drahos 2014:203) as it involves the introduction of new forms of property rights geared towards facilitating exchange in a market system. The second problem is that it means the true value of these knowledge and innovation systems is missed by the global North, particularly the ways in which they suggest the need to expand our epistemic and metaphysical horizons. These lessons are particularly important in relation to climate change, where the value of seeing the earth as a balanced system, a central tenet of many local knowledge systems, has particular resonance (ibid.:206-07). ${ }^{2}$ The final

2 Indeed the most recent calls for paradigm shifts are heavily based upon a revaluing of smallscale, sustainable agriculture that is underpinned by local knowledge and innovation systems. The UNCTAD Trade and Environment Review (2013) argues that small-scale organic farming is the only viable and sustainable way to feed the world and advocates 'a rapid and significant shift from conventional, monoculture-based and high-external-input-dependent industrial production toward mosaics of sustainable, regenerative production systems that also considerably improve the productivity of small-scale farmers'. A similar approach is urged by the final report of the Special Rapporteur on the Right to Food, Oliver de Schutter (2014), who stresses the need for a 'new paradigm focused on well-being, resilience and sustainability' to 'replace the productivist paradigm'. He dismisses the idea that the problem of food security can be addressed through a technological fix, such as by increasing yields, and instead argues that it is essential to change unsustainable consumption habits and to shift towards sustainable production through the adoption of agroecology. This refers to a range of agronomic techniques that reduce the use of external inputs and rely heavily on local farmer knowledge, and are often the techniques being used by the rural poor in the poorest countries of the world today. 
part of the paper then explores one possible approach that could be used in order to make room for these local systems in intellectual property regulation, namely intercultural legal pluralism.

As a preliminary point, it is necessary to discuss a problem of terminology. The term traditional knowledge is widely used to refer to the knowledge held by indigenous peoples that has been transmitted from generation to generation. ${ }^{3}$ However, this definition sets up problematic binaries between traditional and modem knowledge that do not take into account the continually evolving nature of knowledge. It also ignores the importance of local innovation in contributing to developing bodies of knowledge. This paper therefore uses the terms traditional and local knowledge and innovation as an imperfect way of taking account of these difficulties. The final section of the paper argues that the focus should not be on the knowledge or innovations themselves per se anyway, but rather on the knowledge systems of which they are an integral part, thereby also solving this terminological problem.

\section{Local Melanesian Intellectual Property Regulatory Systems}

This section sketches out four local systems that regulate a variety of intangible resources in different parts of Melanesia. These brief descriptions are intended to challenge the hegemonic tendencies of the global intellectual property system and to illustrate the fundamentally different ontological and epistemological frameworks in which they operate. ${ }^{4}$ It should be stressed that these brief descriptions are themselves historically contingent, as systems for the production and use of knowledge are as dynamic and contested in this part of the world as everywhere

3 There is a wide variety of definitions of tradition knowledge (see, for example, Antons 2009:1-4). For example, the Pacific Islands Model Law 2002, discussed below, contains four criteria:

traditional knowledge includes any knowledge that generally (a) is or has been created, acquired or inspired for traditional economic, spiritual, ritual, narrative, decorative or recreational purposes; and (b) is or has been transmitted from generation to generation; and (c) is regarded as pertaining to a particular traditional group, clan or community of people; and (d) is collectively originated and held.

4 Of course such systems exist in many other parts of the world as well. See the excellent literature review by Tom Griffiths (1993) that was kindly photocopied for me by G. Dutfield. 
else. As Simet observes, 'Increasing globalisation threatens the ability of communities in Papua New Guinea to control access to and use of their traditional knowledge' (Simet 2000:78). ${ }^{5}$

The first is a description of part of the intellectual property system of the Tolai people from the Gazelle Peninsula in Papua New Guinea. Jacob Simet, the Executive Director at the PNG National Cultural Commission observes:

Ownership of knowledge among the Tolai is highly regulated, and the ways of acquiring it are clearly defined. Knowledge is owned either by an individual, group or the wider public and may be protected by means of pidik (secrecy). A particular class of spirits known as turangan are present in the creation, transfer and use of knowledge (ibid.:64-65).

He explains that the Tolai recognise five ways of acquiring knowledge: dream, school, gift, purchase and inheritance. The level of ownership is moreover determined by the manner in which the knowledge is acquired. Different spirits are also associated with the different ways in which knowledge is imparted. Even in the case of knowledge gained through attending school, 'the person merely acquires the ability to be associated with spirits that later begin to deliver knowledge to him' (ibid.:65). The rights to knowledge are clearly differentiated from mere access to it:

anyone may know which plant materials are used for healing or other kind of knowledge and may observe the various ritual actions and procedures involved in the performance of healing, knowledge, magic or dance. But they cannot claim ownership of the knowledge these plants and rituals are associated with nor can they practice this knowledge. Rights to knowledge are determined by possession of the wanvul [chant]. At all times the owner of the knowledge keeps this wanvul as pidik (secret) from everyone (Simet 2000:65).

Simet also explains that the Tolai have types of knowledge that is owned by groups, in particular by clans. These clans own tubuan (a type of spirit) designs, magic, songs, dance headdress, necklace designs and the oral history of the clan. In addition, there is also public knowledge that everyone in that society knows or has a right to access, including marriage

5 The section that follows is extremely indebted to the project led by anthropologist Marilyn Strathern in the late 1990 s to early 2000s that investigated issues of cultural property in PNG. Their scholarship, as well as other anthropological works, reveals complex and varied intellectual property regimes. See Hirsch and Strathern 2005; Kalinoe and Leach 2004. 
procedures, gardening and fishing techniques, some songs, dances and rhymes. This knowledge is, however, only public in the limited sense that everyone in the village has access to it and can utilise it. There are complex rules regarding the rights of those in neighbouring villages and those who are related to those from the village, but now live in distant villages, to use the knowledge. Tolai society also recognises that there are 'others' beyond this defined public who may use their public knowledge. However, in such a case the worst that can happen to them is that they will be ridiculed or made fun of. The normal rules of ownership, rights and claims are not applied here' (ibid.:76).

A second description comes from Stern, an ethnomusicologist, who describes the way in which the production and use of music occurs in North Vanuatu as follows:

In Vanuatu some people are recognised as song specialists, a kind of composer ... Maurice, an elderly composer ... explained to me that, if someone commissions a song from him, he composes it and gives it to the person in exchange for a payment. The composer himself must forget the song, because, henceforth, it belongs to the person who commissioned it. The explanation of the 'forgetting' composer is very explicit concerning the existence of rights to music ... There is a close connection between spirit entities and composition. Most of the time, people believe that a song or a dance was brought to the living ancestors' spirits in dreams while asleep or walking alone in the bush ... This super-natural origin of songs is an important part in the conception of rights because it plays a large part in the protections of songs ... Magic ensures that [the rule over payment and transfer of rights] is respected (Stern 2013:59, 64-65).

However, she also notes that there are some categories of music that are inalienable and can only be transmitted within a specific group of people. Two examples of these are magic songs that influence the weather and tides, and songs that testify to ownership of a particular piece of land. In both cases these songs can only be transmitted inside a group along specific kinship relations and it is kept secret. She observes, 'Knowledge belonging to one group of people—genealogies, family histories, artistic knowledge, magic learning etc.- gives this group a common identity and, as it were, a certain prestige over others who do not share this knowledge' (ibid.:66-67). Finally she describes particular types of music exchanges that can only take place within a particular hierarchical grade system that is based upon political and economic competition. To move up through 
this grade requires the initiate to acquire a certain amount of cultural wealth, and once the grade is achieved the holder is entitled to rights to 'a certain reserved musical repertoire' (ibid.:68). Stern comments that:

Knowledge-music, names, dances etc.- is prestigious and requisite to access a social and political rank ... the exchanges of which music is part, are also an important way of consolidating social relationships. An individual relies on his/her relationships to directly access different kinds of knowledge and hierarchical grades implying them (ibid.:71).

Once the knowledge is acquired it is kept secret, and this creates a special bond between the initiates. It also means that the right to publicly perform a secret song confers greater prestige. ${ }^{6}$

The third example comes from the Rai Coast of Papua New Guinea. Anthropologist James Leach describes some of the intellectual property and cultural property questions that arose at the local launch of a book he co-wrote with Porer Nombo, a man from the area, about local plants and their uses:

Porer was meticulous throughout our collaboration to include only plants that he had direct understanding of and for which he could trace the route (people, kinship connection) through which he knew them. For example, during the collecting work for the first edition of the book in 1995, we stumbled across a plant (used for love magic) in the bush, photographed and discussed it, but then removed it from our records because as we talked Porer realised that it is central in a myth told by people from the neighbouring village of Serieng. While everyone who knows the myth knows the possibilities for its use, the myth named ancestors of other people. Porer was not in a position to use the names of those people (Leach 2012:258).

Porer told us that he had been given recognition as a person (a person who was in a position to receive and utilise these names and plants) by the acceptance of pigs, shells and other things by his mother's brothers and wife's kin during the course of many ceremonies. That what we were calling 'knowledge of plants' was a part of his relation to them, and thus part of his position, his very constitution (ibid.:260).

6 The song is kept secret even though publicly performed because the initiates dance to the rhythms of rattles worn on their feet and beat bamboo drums, but the inaudible songs arc performed only in their heads so as not to reveal them' (Stern 2013:67). 
Leach also describes how a decision was made in the creation of the book to leave out certain parts of the knowledge about the various plants described. The parts left out were the names of characters in myths and tunes from those myths that are 'a crucial part of the effect of many of the plants in our book' (ibid.:259). This was done consciously both to protect the secrecy of the knowledge and to require those searching for that knowledge to go to Porer and to be given access through the right channels. Leach paraphrases Porer as saying:

If you want these things to work for you, come and talk to me or to others who have received them through the right channels. Come and ask respectfully and I will give them. But they are not simple keys. There is 'hard work' involved (ibid.:259-60).

A final example concerns taro (a staple root crop) and taro production, in Solomon Islands and comes from a study by the Solomon Islands Planting Material Network and Kastom Gaden Association. The report states:

Cultivation and ownership of taro landraces and knowledge takes place in the context of mutual kinship obligations and competition for control of important resources, which are central components of Melanesian culture ... Some farmers maintain landraces of taro that they do not share easily with others. These may be traditional landraces that have been grown by their clan or line for generations. They may be special landraces acquired by a farmer that he/she does not want others to have in order to have an economic or social advantage. Farmers expressed feelings of advantage, respect, power and prestige in having landraces of taro that other people did not have. Such taro can be used to advantage during feasts, sharing through social obligations, and sometimes in marketing. Hidden taro landraces were often associated with hidden taro 'kastom' or knowledge that allowed successful taro farmers to produce good taro crops and hence gain social status and respect (Jansen 2002:20).

The report also describes three different ways of naming taro cultivars. The first is to name the taro after the place it came from, this could be the name of a village or another island. Second is to name taro after the person who 'discovered' them in a garden (new landraces of vegetatively propagated crops such as taro appear sporadically amongst crops of other cultivars as a result of random mutation and must be identified as new by the farmer), or the person who introduced them to the area. The third is to name cultivars after a situation or circumstance that led to the acquisition of the taro landrace. The author states: 
For example a commonly planted cultivar in Temotu is named 'selfis' (selfish) because one farmer who grew it refused to share it with others. It was presumably eventually stolen from her garden (ibid.:19).

These brief descriptions of some of the systems of regulation over intangible resources in Melanesia reflect a number of important features. First, the systems of regulation are embedded within the social, cultural and political context of the societies they regulate. As such, they resonate with the observation of Curry, a human geographer, that one cannot separate the economy and society from each other in Melanesia because 'the economy is intensely social and the social is intensely economic' (Curry 2003:419). Second, the systems of regulation both reflect, and are bound up with, questions of relationships between different groups and between individuals and the group. In this respect they reflect a relational ontology, by which I mean a world view or basic assumptions about the kinds of entities thought to exist in the world (Escobar 2010:4). Escobar has observed that relational ontologies:

can be differentiated from the dualist ontologies of liberal modernity in that they are not built upon the divides between nature and culture, us and them, individual and community; the cultural, political and ecological consequences of taking relationality seriously are significant; relationality refers to a different way of imaging life (ibid.).

This point about a different ontological framework is also clear from the frequent references to spirits and magic, which are viewed as essential elements and part of the complex networks of relationships and power structures that bind society together. This is still a widely held viewpoint in many parts of the region. For example, in the archipelago nation of Vanuatu, a joint project was recently established between a range of government departments, academic institutions and donors to deal with the meteorological implications of climate change. ${ }^{7}$ In a meeting to discuss the project on one of the islands in 2013, it was reported that the chiefs highlighted a number of contributions that could be made, including traditional cropping calendars and practices and traditional climate change adaptation processes. The chiefs also stressed as 'essential', however, the acknowledgement and valuing of the contribution of local

7 A similar project was developed in Africa (see Ziervogel and Opere 2010). 
weathermen, called tupunas, who have an important and widely recognised role in enhancing agricultural production and enabling food security for communities on Tanna Island (Government of Vanuatu 2013).

The references to spirits and magic in the descriptions also draw attention to the very different conceptualisation of creativity and innovation that are at play in these societies. In particular, inspiration and new ideas are said to come from spirits and dreams, and not to be attributable to the individuals who first voice them, rendering the notion of authorship in copyright rather meaningless. Lindstrom observes:

Islanders do not explain their production of songs or other new knowledge in terms of a knower's individual talent, genius or creativity. Local epistemology seeks authorities and not individual authors ... the Tannese intimate that they are repeating truths told by their fathers, whispered by spirits when intoxicated by kava, or revealed by ancestors in dreams (Lindstrom 1990:316).

Further, in many Melanesian societies, the value of creativity is located in productive relationships, and not in things (Leach 2005; Lindstrom n.d.). Brazilian anthropologist Viveiros de Castro similarly argues that among the Amerindian of Amazonia, culture is not seen as a product of invention, but of transference, a borrowing of prototypes already possessed by animals, spirits or enemies. 'The idea of transformation/transfer belongs to the paradigm of exchange' (de Castro 2004:477). The difference between the creation paradigm (poiesis) and the transformation paradigm (praxis) is said to be:

In the creation paradigm, production is causally primary; and exchange, its encompassed consequence. Exchange is a 'moment' of production (it 'realizes' value) and the means of reproduction. In the transformation paradigm, exchange is the condition for production since, without the proper social relations with nonhumans, no production is possible (ibid.).

Thus the magical dimensions of these intellectual property systems once again point us back to the fundamental importance of social relationships. Third, these regulatory systems operate at a non-state level and are administered by local leaders and based on customary norms, thus demonstrating that the state centralist orientation of the global intellectual property system is not the only regulatory possibility. This alerts us to the opportunity for regulatory agency at a variety of different levels: local as well as state and international. Finally, these regulatory frameworks demonstrate a very different epistemological framework to 
the dominant one used in the global North where knowledge can be, and often is, objectified. In Melanesian societies, in contrast, 'all knowledge is subjective knowledge ... there can be no detachment of the knower from the known as in mainstream Anglo-European epistemology' (Gegeo and Watson-Gegeo 2001:62). This point is developed further below.

In concluding this section, it is important once again to acknowledge that today the societies within which these intellectual property systems are situated are changing fast, and new claims of ownership and registers of creativity arc becoming more prevalent (see Dalsgaard 2009; Geismar 2013). However, before too hastily discounting these existing systems and replacing them with shiny new TRIPS-compliant regimes, it is important to reflect on what is lost in so doing, and whether there are benefits in preserving at least elements of them.

\section{Two Sites of Colonisation?}

Having established the existence of a range of alternative intellectual property systems in one small region of the world, I now turn to consider two ways in which these systems and others like them are being, or risk being, marginalised and undermined. The first is through the increasing web of regulation of traditional knowledge by national and international bodies, and the second is through the identification of the informal economy as a new domain in which global intellectual property rights are required.

\section{The Regulation of Traditional Knowledge}

Traditional and local knowledge is currently the subject of, or impacted by, multiple actual and proposed new regulatory regimes. This attention has been occasioned over the last decade by a range of concerns, including bio-prospecting, misappropriation, ensuring equity in the global intellectual property regime, the possibilities of traditional knowledge and local or grassroots innovation for development in the global South and amongst indigenous communities, and finally as part of claims of indigenous communities across the globe for recognition of their human rights and rights to their cultural heritage. The current international framework comprises the Convention on Biodiversity, TRIPS, the International Union for the Protection of New Varieties of 
Plants Convention, the Nagoya Protocol, the International Treaty of Plant Genetic Resources for Food and Agriculture, the United Nations Declaration on the Rights of Indigenous Peoples, the UNESCO Convention for the Safeguarding of Intangible Cultural Heritage 2003, and the International Labour Organization Convention 169 on Indigenous and Tribal Peoples in Independent Countries. There are also ongoing negotiations over the formulation of international instruments being carried out under the auspices of the World Intellectual Property Organization (WIPO) Intergovernmental Committee on Intellectual Property, Genetic Resources, Traditional Knowledge and Folklore (the IGC). These various different frameworks are beyond the scope of this paper to describe in detail, and indeed this has been done expertly elsewhere (see, for example, Tobin 2013:142).

At a regional Pacific Islands level, there are also a number of relevant legal frameworks, including the Melanesian Spearhead Group Treaty on Traditional Knowledge (still not ratified in 2015), the Pacific Model Law for the Protection of Traditional Knowledge and Expressions of Culture 2002, and the Pacific Model Traditional Biological Knowledge, Innovations and Practices Act 2001 and associated guidelines. At a national level in the Pacific Islands region, there is draft legislation in a range of countries (Fiji, Vanuatu, Samoa, Solomon Islands), and the Cook Islands recently enacted its Traditional Knowledge Act 2013. There are also specific provisions relating to traditional or indigenous knowledge in a range of existing pieces of intellectual property regulation. ${ }^{8}$

Whilst there is a good deal of variation in the approaches of these different regulatory regimes, most of them focus on drafting new legislation, centralising the state as the regulator of traditional knowledge and creating exclusive property rights in traditional knowledge that are vested in communities or groups (see Forsyth 2011, 2012, 2013a). In general, the international treaties and legislation actually in force or in development deal with traditional knowledge by conceptualising it as another subject-matter for the global intellectual property regime to regulate. This is entirely consistent with the dominant, economics based, Anglo-American approach to intellectual property that views intellectual property rights essentially as commodities, in which their fundamental value is to produce revenue. Thus, although these approaches are often

8 For example, Part 7 of Vanuatu's Copyright and Related Act 2000 and Section 30 of Samoa’s Copyright Act 1998. 
referred to as sui generis, in many respects they are simply extending the global intellectual property system, rather than trying to regulate traditional knowledge in a truly original way. This can be seen by the way in which the IGC has divided traditional knowledge up into separate categories of traditional knowledge associated with genetic resources, traditional knowledge and traditional cultural expression, thus following western intellectual property categories and undermining indigenous understandings of the three areas as intrinsically linked. Traditional knowledge is seen as being able to be abstracted from the social context in which it has been developed, and turned into a form in which it can be traded in the global market. This economic focus is reinforced in the area of genetic resources and their associated traditional knowledge by an emphasis on benefit-sharing agreements (see Kariyawasam 2008:84; WIPO 2013). As pointed out by an increasing number of scholars, however, this is problematic because the focus on compensation and justice has led to the sidelining of the need for nurturing traditional and local knowledge and innovation (Robinson 2008), and has also led to numerous cases of community conflict (see, for example, Peteru 2008; Vermeylen 2013).

Whilst these new developments are certainly preferable to ignoring the intellectual property issues surrounding the global North's recent appreciation of the value of traditional knowledge, it is an extremely limited approach. It fails to take into account the ontological and epistemological context from which the knowledge and innovation arise; instead embedding them within global normative frameworks that operate according to a very different register of value. This follows the same fallacies that were tried, and failed, with regard to transforming customary land and marine tenure into exclusionary and restrictive Western legal categories (Vierros et al. 2010). Bragdon makes similar observations in the context of discussions about genetic resources and local knowledge:

Currently, the focus of discussions in intergovernmental fora, including the IGC, is on traditional knowledge over traditional resources and not on this dynamic technology development process by farmers where all gennplasm-modern or traditional-is treated as potential input for direct use or further improvement. In international fora the emphasis is on genetic resources per se and the role of farmers in conserving local and traditional landraces, rather than on the innovative process by which genetic resources are continually refined and developed (Bragdon 2013). 
Related problems can be identified in the tendency to value traditional cultural expressions purely for their aesthetic and commercial purposes in the development of new economic opportunities amongst indigenous populations. For example, in referring to the regulatory strategy over sand drawings, an important part of Vanuatu's cultural heritage, the Director of the Vanuatu Cultural Centre stated:

the drawings are often showcased as a form of decorative folklore for the tourist industry and other commercial purposes. If left unchecked, this tendency to appreciate sand drawings on a purely aesthetical level may result in the loss of the tradition's deeper symbolic significance and original social function. Sand drawing is a fundamental form of traditional communication and conceptualization, which has the potential to play a central role in developing cultural identity and maintaining cultural continuity for communities in Vanuatu through the promotion of creativity and the preservation of diversity (Vanuatu Cultural Centre 2010).

The economic focus that is being adopted in regard to the regulation of traditional knowledge can also be demonstrated by the virtual exclusion of customary law from the treaties being developed, and its marginalisation in much existing and draft traditional knowledge statutes. Thus Tobin has observed that the IGC draft treaties have been increasingly 'shorn' of their references to customary law, and that the European Union's 2012 draft treaty for the implementation of the Nagoya protocol makes no reference at all to customary law and restricts protection to a small fraction of traditional knowledge (Tobin 2013:161). Customary law is seen as being too uncertain to be used within a market-based system in which the concern is to ensure ease of use for the 'buyers'.?

\section{Intellectual Property and the Informal Economy}

This concern with the way in which traditional knowledge is becoming another site for the expansion of the global intellectual property regime, and its reductionist economic focus, is mirrored by parallel developments in regard to local innovation. There are a number of current projects and scholars seeking to find ways to make intellectual property work for the

9 For a discussion (and refutation) of the perception of customary law as 'uncertain', see Forsyth $2013 b$. 
world's poor. ${ }^{10}$ For example, Madhavi Sunder argues that 'intellectual property rights in poor people's knowledge are increasingly considered a key to third-world development' (Sunder 2007:111). She observes:

after a decade of resisting the Western imposition of intellectual property, now many in India - from the intellectual property professors and lawyers in the cities to the farmers and artisans in the villages-were beginning to ask: how can intellectual property rights work for them? TRIPs protected the knowledge and economic interests of the developed world, the rich corporations of the West. Can intellectual property be a tool for protecting poor people's knowledge as well? Many seem to think so (ibid.:98).

As part of this new interest there is an emerging focus on the way in which intellectual property rights can be used as a stimulus for innovation in the informal economy. For example, following recommendation 34 of the 2007 WIPO Development Agenda 'to conduct a study on constraints to intellectual property protection in the informal economy', a study was carried out on the link between informal economy and intellectual property through three country studies in Africa (De Beer at al. 2013). At a presentation of the findings at the WIPO Committee on Development and Intellectual Property meeting in May 2014, a number of panellists observed that the project revealed the extent of innovation occurring in the informal sector that had hitherto been overlooked. Sacha Wunsch-Vincent, senior economic officer in the WIPO Economics and Statistics Division, characterised it as 'constraintbased innovation' that mostly consists of adapting, applying and improving existing knowledge' (Astruc 2014).

This WIPO project is complemented by a growing body of research into what is sometimes referred to as grassroots innovation (De Beer et al. 2013:18). Emerging research shows that grassroots innovation occurs in the context of particular social and cultural understandings about the use and transmission of knowledge, and is often subject to non-state systems of intellectual property regulation, such as informal contracts, codes of access and customary norms. For example, wind turbine development can originally be traced to a culture of collaborative craft production and

10 For example, the World Bank published a report that presented a range of case studies demonstrating the importance of 'promoting the innovation, knowledge, and creative skills of poor people in poor countries, and particularly about improving the earnings of poor people from such knowledge and skills' through the use of global intellectual property rights (IPR) (Finger and Schuler 2003). 
a tradition of cooperative organisation in Denmark. Ely et al. observe that 'Social networks built up shared knowledge, experience and ideas about turbine construction and use' (Ely et al. 2013:107).

While WIPO's informal economy project is extremely valuable in starting to chip away at the notion that innovation only occurs within the formal economy, it raises the question about whether the project may lead to a colonisation of this new space by the global intellectual property regime, rather than being used as a springboard to explore fresh approaches about the regulation of innovation and creativity in the informal economy. There are suggestions that this project may be used to develop policies to move people from using 'alternative knowledge appropriation strategies' to formal intellectual property. For example, Herman Ntchatcho, senior director of the Department for Africa and Special Projects of the WIPO Development Sector, stated that, 'recognising interactions between formal and informal economics, at some stage of the journey many of the entrepreneurs need to move to the more formal spheres of activity, particularly where IP and innovation are concerned' (Astruc 2014). This reflects the same type of 'imperial narrative of progress and advancement, a narrative which posits some societies as having achieved its promise and as other still en route towards it' that has proved so problematic in development to date (Pahuja 2011:212). Further evidence of the potential for colonisation comes in a policy recommendation at the end of the central study paper that 'an important policy challenge will be to make IE [informal economy] actors aware of the possibilities that formal IPRs offer' (De Beer et al. 2013:48). This informal economy example is just one of many components of the current expansion of the global intellectual property system into the developing world on the uncertain premise that it promotes 'development' and is necessary in the absence of existing regulatory structures. ${ }^{11}$

11 This argument is developed at length in Forsyth and Farran 2015. 


\section{What are the Problems with Overlooking Local Intellectual Property Systems?}

We have just seen that two areas of local knowledge and local innovation are being increasingly threatened with being enclosed within an intellectual property regime that focuses purely on economic considerations at the expense of the social and the cultural. This gives rise to a range of potential problems, but here I focus on just two.

First, the creation of new forms of property rights is likely to interfere with the operation of the existing local systems in a variety of problematic ways. The narrow economic focus that the global intellectual property regime brings to bear on the regulation of traditional knowledge creates the risk that the real benefits of local knowledge and innovation for development may fail to eventuate for the same reasons that the economic focus of the development project itself has not resulted in the anticipated benefits for the global South (see Collier 2007; Easterly 2006; Escobar 1995). In particular, it glosses over key issues about distribution of benefits and ensuring equitable access to resources. The establishment of new market-based regulatory systems over tangible resources, such as land, has a history of enabling resources that were once of broad benefit to large numbers of people to be effectively captured by a small and closed group of people. This small group is often comprised of male elites and then of foreign corporate interests at the last stage of the commodification process. ${ }^{12}$ Similar consequences are likely to flow from a market-based approach to traditional knowledge regulation.

In this respect, there are real lessons to be learnt from the work of those who have investigated the problems created by the transformation of customary tenure into western-style property regimes (Fitzpatrick et al. 2012; Platteau 1996, 2000) and also the breakdown in social relationships caused by the transformation of labour into a market-based paradigm in Melanesia (see, for example, Curry and Koczberski 2012). The expanding bodies of literature in these fields demonstrate that the social tensions caused by disputes over how to calculate and distribute resource rents have led to the phenomena known as the 'resource curse', whereby developing countries that are resource rich often struggle to translate their wealth

12 Economist Thomas Piketty predicts that the upper 10 per cent will have about 60 per cent of all income by 2030 (Piketty 2014). 
into broad-based development and social conflict eventuates (see Bainton 2010; Filer and Macintyre 2006; Regan 1998). However, although generally pessimistic, there are a number of hopeful directions emerging from this literature-for example, the diverse economics approach that rejects what J.K. Gibson-Graham has termed 'capitalocentricism' and explores alternative economic models that coexist with capitalism in a variety of contexts (Gibson-Graham 1996, 2006). These demonstrate the possibilities and benefits of experimenting with ways to adapt global or western regulatory schemes in ways that are more congruent with existing regulatory structures, and which take into account a relational perspective, as developed below.

These observations lead me to suggest that attempting to regulate local knowledge and innovation through a purely economic, positivistic framework risks creating significant harm through the disruption of the social relationships upon which this knowledge and innovation is currently produced. Disregarding existing relationships jeopardises valuable knowledge-exchange networks, social capital and trust that are not only essential to meeting economic objectives, but also social, cultural and political needs, and also are an important incubator for future knowledge and innovation generation. As Leach and Davis note:

different registers of value locate knowledge in relation to something else and this can create hierarchies, appropriation, replacement or elision of pre-existing values. While knowledge may create value, new value does not always supersede previous value, sometimes an entity carries more than one value, more than one set of relationships (2012:221).

Reducing the way in which knowledge is viewed to an economic perspective thus risks prioritising one set of values over others, and in turn reordering existing relationships. This is certainly not to say that existing systems need to be kept unchanged, or that without support or adaptation they can meet all the new demands that regulation of intangible resources involves today. However, in creating regulatory frameworks in this area, cognisance does need to be had of the existence of such systems and the various social, political and economic roles they play.

The second main problem with overlooking existing intellectual property systems is that their value is missed by the global North, particularly the ways in which they suggest the need to expand our epistemic and metaphysical horizons. As suggested in the introduction, the tendency to overlook existing non-state regulatory systems comes from a western 
epistemic tradition of objectifying knowledge. This can be illustrated by the way in which traditional ecological knowledge is starting to be used by climate change projects in Pacific Island countries. Over the past decade, attention at both global and domestic levels has started to be paid to the potential of traditional knowledge and local or grassroots innovation in a range of developmental contexts, and particularly in the context of climate change adaptation. ${ }^{13}$ Both are seen as possessing great potential utility for assisting the global South to manage the various crises associated with climate change, such as problems of food security and coping with extreme weather events. For example, attention has been drawn to the value of traditional navigation systems, traditional resource management, traditional fisheries systems, and vernacular architecture (UNESCO 2013). At the Pacific Climate Change Roundtable in Nadi, Fiji in 2013, the importance of combining science and traditional knowledge was stressed. The Director General of the Pacific Regional Environmental program highlighted the importance of the practical application and blending of modern science with traditional knowledge, stating, 'The value of good science must be blended with traditional knowledge to address related climate change issues affecting the region today'.

Many of these traditional ecological knowledge projects, however, adopt a very narrow view of the benefits of traditional knowledge, seeing it essentially as an object that can be extracted from its social context and applied within a western scientific framework. For example, there are currently a number of organisations compiling databases of various aspects of traditional knowledge in the Pacific Islands region, and also a number of projects that seek to collect traditional knowledge and then validate it against scientific knowledge (see Chand et al. 2014; Narsey Lal et al. 2009). Typically such projects compile such knowledge in a way that emphasises the instrumental value of the knowledge from a western scientific perspective, isolating it and decontextualizing it from its cultural context. Margaret Jolly comments on such processes, noting:

typically such processes have been leached of their cultural or spiritual significance, flattened and reduced to secular techniques which can hopefully be remembered and recreated in the face of future catastrophe ... Selectively collecting such indigenous knowledge and practice and corralling it under the acronym TEK [Traditional Ecological Knowledge] seems to demean both the immensity of the problem, the indigenous

13 See the literature review in McNamara and Prasad (2013). 
knowledge itself and Pacific peoples' creative capacities for survival in drastically changed circumstances, including their appropriation of western science (2014).

Such projects are certainly not concerned with the spiritual and magical dimensions of traditional and local knowledge. In one way this is a good thing, as it means that attempts are not made to trespass on areas of knowledge that are considered highly secret and restricted by local populations. It can also be argued that it is not strictly necessary as epistemic cooperation/convergence between two cultures operating with radically different metaphysical schemes is possible-for example, at the level of sharing observations about the properties of plants (Claudie et al. 2012). However, the relative invisibility of this dimension to Western scientists, and its ready dismissal, is symptomatic of a blindness to the different world views in which traditional and local knowledge is produced. This is problematic because it limits the ability of climate scientists and others in the global North to be challenged by the possibilities of reframing the types of research problems they are investigating. As Drahos argues, juxtapositions of people from different cosmologies is more likely to lead to de-routinisation, a 'process in which actors begin to question their adherence to conventional routines of thought and behaviour' (Drahos 2014:209). This in turn creates the types of conditions necessary for the bold conjectures that Popper argues are necessary for the advancement of science (Popper quoted in ibid.:205-07). These insights are, however, not likely to arise if merely instrumentalist use is made of local knowledge by outsiders: it is necessary to at least be aware of the different ontology within which the knowledge is situated, to respect it, and preferably to be prepared to walk around a little inside it. As Quijano, the renowned Peruvian sociologist, points out, intercultural communication can only occur if each party to the dialogue recognises the partiality of their perspective (Quijano 2007:177).

Exploring a new ontology may, for example, allow us to see important connections between different phenomena that our own ontology does not perceive a relationship between. ${ }^{14}$ For example, anthropologist James Leach describes how the Rai Coast people of PNG have certain magic procedures that are necessary to make plant medicinal knowledge effective for them. Yet he observes that these are left out of descriptions of the processes in order for those processes to appear as 'knowledge' to

14 For an excellent example of such an intellectual endeavour, see Wen-yuan Lin and Law 2013. 
outside observers (Leach 2012). He argues that taking the magic out of the definition of this knowledge means overlooking the key role that the magic performs-namely, 'the effective positioning of persons in relation to one another' (Leach and Davis 2012:214). Similarly, Cruikshank demonstrates how certain narratives about glaciers as 'knowledge' for climate scientists and government agencies means leaving out what makes them actually effective for the native people in the Yukon (Cruikshank 2012). Leach and Davis thus observe:

The effect of the recognition of these practices as knowledge in both cases is to make them less effective, or render them incomprehensible and useless, as the definition of knowledge employed by those in a position to make the recognition is not only narrow, but colonising in the sense of only admitting certain sources of effect [i.e. rational and scientific and not magical] (2012:213).

Creating awareness of the local intellectual property systems within which local knowledge and innovation are embedded is one way of making the different ontological and epistemic perspectives at work apparent. This in turn is more likely to promote the type of profound questioning likely to occasion much-needed scientific paradigm shifts, particularly those related to climate change. For example, going back to the Vanuatu meteorological example raised before, what might happen if, rather than focusing on integrating traditional weather indicators into a western knowledge framework, the tupunas (weathermen) and their powers, were seen as a pivotal part of the study as the local chiefs suggested? This may lead to truly transformative ways of thinking about the natural world and relationships between man and nature, rather than merely thinking about local knowledge in purely utilitarian ways (Cruikshank 2012:240; Vermeylan 2010). For example, they may help to break up many of the binaries within which western science is currently constrained (nature vs culture, mind vs matter), which some leading indigenous scholars, such as Vivieros de Castro, argue have impoverished 'modern thought' (de Castro 2004). He shows how engaging with different ontological frameworks, and thereby taking seriously their different divisions between nature and human, is absolutely essential if we are really interested in learning from indigenous knowledge. 


\section{Making Room for Magic: A Pluralist and Intercultural Approach}

One way to engage with alternative perspectives to the dominant intellectual property paradigm is to adopt a pluralistic and intercultural approach. This approach is based upon a recognition that there are many different models of intellectual property regulation both possible and currently in existence, of which the global system is just one. These alternative systems include indigenous knowledge systems, informal norms built up among group members over time, trade secrets, codes of conduct and informal contracts. Further, these different systems are culturally, historically and politically contingent, and are in a continual process of contestation and transformation as a result of their interaction with each other, and with other forces such as colonisation and globalisation. A pluralist approach is one that recognises the need to make space for consideration of these different systems, and an assessment of their respective merits and capacities for change in meeting new challenges and regulatory requirements.

A pluralist approach thus rejects the pretences to universalism that are apparent in the dominant intellectual property system, whereby it is positioned as being the only valid system to deal with all aspects of the regulation of intangible resources, even traditional and local knowledge and innovation. It requires a commitment to a pluralistic process along similar lines to that advocated by Berman:

We might deliberately seek to create or preserve spaces for productive interaction among multiple, overlapping legal systems by developing procedural mechanisms, institutions. and practices that aim to manage, without eliminating, the legal pluralism we see around us (2012:10).

A pluralistic approach does not necessarily prioritise any system, nor does it reify or romanticise non-state systems, or overlook their need and capacity for change. ${ }^{15}$ Simply it means that that due attention should also be paid to them by the international community, donors, nation states and local communities as a possible focus for protecting traditional knowledge.

15 These are some common but misguided criticisms made of legal pluralism. See, for example, Porter 2012. 
Such a pluralistic approach should be complemented by commitment to interculturality, which recognises the need for dialogue and real communication between those who represent different systems, from a position of mutual respect. Walsh explains this concept as follows:

It allows imagining and opening of pathways towards a different society based on respect, mutual legitimacy, equity, symmetry and equality where difference is the constitutive element and not merely a simple addition. Interculturality also requires an understanding that behind the relations to be constructed—among groups and between the structures, institutions and rights that the state might propose-are distinct logics, rationalities, customs and knowledges (2009:79-80).

Applying this notion to a legal context as an illustration, Tobin describes intercultural legal pluralism as 'a world of legal interfaces that cannot be imposed but must be negotiated, tested and modulated in response to the realities of differing worldviews, value systems and legal visions' (2013:161). In relation to intellectual property, the concept of interculturality is important because it highlights that attention must always be paid to the social and cultural context of intellectual property regulation. It also requires us to explore, rather than assume, local understandings about the value of knowledge, the meaning of innovation and the stimulus for creativity. The development of regulatory frameworks at local, national and international levels for local knowledge and innovation therefore require engaging with the different ontological and epistemological perspectives involved, and making spaces for the differences in opinion and values that these entail to be articulated and discussed.

Some mechanisms that may be usefully considered to advance both a pluralistic and an intercultural approach to intellectual property are as follows.

\section{Reconceptualise Traditional Knowledge as Being about Local Knowledge Systems}

As discussed above, local knowledge is currently conceptualised in international and national regulatory frameworks as a static, 'traditional' object that exists independently of the social, political and economic structures that have in many ways produced it. Very similar assumptions are often made about customary law, as demonstrated by a continuous string of failed attempts since colonial times to codify customary norms (Engle Merry 1991:867). However, as I have argued elsewhere, both 
customary norms and traditional knowledge are deeply embedded within their social and cultural context (Forsyth 2011). Although indeed one particular item of knowledge can be separated and treated as an object, this would ignore the processes that led to its production in the first place, the continuation of which is far more important than ensuring the preservation of particular items of knowledge at a particular moment in time. Further, these practices have not stopped, but are ongoing, as existing knowledge is adapted and blended with new knowledge in innovative ways.

I therefore suggest that we start to think of local knowledge and innovation as being part of living, changing and adapting systems. This approach sees knowledge and innovation as based on cycles of knowledge creation, use, dissemination and more creation. It rejects the current binary between traditional and modem knowledge and requires us to pay attention to the conditions of the social structures, including their regulatory mechanisms, within which they operate. These knowledge systems furthermore reflect the priorities of particular societies, and demonstrate their underlying cultural values, such as respect for the wisdom of elders, connections with the spirit world, the primacy of social relationships, connections with place and land, and so forth. This approach also garners support from the suggestions recently made by Drahos and Frankel that, rather than focusing on the knowledge itself, it is more useful to focus on the system of indigenous innovation:

The generation of useful knowledge and techniques implies a set of institutions working in convergent ways to produce innovation. A systems perspective on innovation requires one to look more broadly at the institutions that contribute to innovative performance, as well as the distinctive linkages and interactions amongst institutional actors that characterise an innovation system (Drahos and Frankel 2012:4).

As they observe, adopting this perspective then suggests a variety of different questions to the usual one of 'how do we protect traditional knowledge?' such as 'how indigenous innovation might be supported?' How collaboration may be encouraged 'between cosmologically anchored indigenous networks and scientific networks?' and 'how can we turn indigenous networks into development networks?'(ibid.) 


\section{Use Vernacular Languages}

Another mechanism that furthers a pluralistic and intercultural perspective is the use in state legislation of vernacular terminology. The use of vernacular language in state laws can destabilise assumptions that terms are read and understood by those from different cultural backgrounds in the same way. This is of particular importance in countries where there are indigenous minorities. For example, the revised New Zealand Patent Act 2013 creates a Māori Advisory Committee similar to that existent for trademarks. Members must, 'in the opinion of the Commissioner', have knowledge of te ao Mãori and tikanga Mãori (Lai 2013). The use of these vernacular terms signify that there are different epistemological frameworks at play that need to be considered. Another example is the use of $u B u n t u$, an indigenous South African value, by the Constitutional Court and by other levels of the judiciary in South Africa (Cornell and Muvangua 2012).

\section{Use Indigenous and Local Institutions}

A further very important mechanism is the use of indigenous or local institutions in the regulation of local knowledge and innovation systems. As found in a 2003 report of a Consultancy for the Capacity Needs Assessment on Access and Benefit Sharing and the Protection of Traditional Knowledge, Practices and Innovations for Samoa:

Traditional knowledge in particular is inextricably woven with the $f a^{\prime} a$ Samoa [the Samoan way]. Any access and benefit sharing scheme needs to incorporate the fa' $a$ Samoa and build upon that sense of ownership in order to be successful. The consultation outcomes also demonstrated that any scheme to regulate access and benefit sharing must be undertaken as a partnership between central government and villages (Urwin Consulting 2003:31).

I have discussed elsewhere the importance and the difficulties in engaging in this type of pluralist endeavour, and the need to avoid the mere referencing of customary law or customary institutions while at the same time effectively disempowering them (Forsyth 2011). A recent example of national legislation that recognises meaningful roles and responsibilities for indigenous customary institutions is the Cook Islands' Traditional Knowledge Act 2013. This centralises the Are Korero, which is the traditional meeting house in the Cook Islands (Buse and Taringa 1995), in both the process of the registration of traditional knowledge and decisions about entitlements to rights over traditional knowledge. 


\section{Take Account of the Values and Principles Underlying the Existing Systems}

A final mechanism is to extract and reference the values and principles that underlie local intellectual property systems in the creation of new regulatory regimes. This follows Drahos' suggestion that 'simple rules and principles offer the beginnings of a regulatory system that engages seriously with indigenous peoples' knowledge systems' (Drahos 2014:101). Principles are able to 'permeate and orient' a regulatory system (ibid.), and are particularly important when establishing new regulatory systems, as they offer important guidance for the future development of the system. Pacific Islands peoples have engaged in a similar exercise in their ongoing development of local research methodologies. These new methodologies fundamentally challenge the dominant Eurocentric approaches and involve new approaches based on indigenous epistemic practices and codes of ethics (see, for example, Smith 1999; Vaioleti 2006).

\section{Conclusion}

In conclusion, I wish to briefly reflect on what the above exegesis of local Melanesian intellectual property systems can offer for critical intellectual property discussion more broadly. There are two broad observations that emerge. The first is the value of plurality in this field that is currently so heavily dominated by standardisation and a quest for uniformity. The preceding discussion suggests that there are serious side effects of a uniform approach to intellectual property regulation, and that it can even undermine the conditions that are most likely to lead to innovation and creativity in all its wondrous diversity. In other words, although seeking to incentivise further creativity and innovation, the global intellectual property system is actually gradually homogenising the conditions in which creativity and innovation is produced. Ironically, and almost certainly, this is likely in the long run to lead to less creativity and innovation, or at least less radical and heterogeneous creativity and innovation. The examples from Melanesia illustrate that it is a mistake to try to separate the systems that regulate intellectual property from the resources themselves. Therefore, if as a matter of global policy we really do value innovation, in its real sense of offering true alternatives and new directions, we should also recognise and value alternative intellectual property mechanisms to the dominant global model. Although these systems are more apparent in places such 
as Melanesia where the global intellectual property system has not as yet established a strong hold, they exist throughout the world in areas such as the informal economy and elsewhere there are intangible resources not currently regulated by the global system. I suggest that rather than merely accepting as inevitable their ultimate domination by the global system, there is exploration of ways in which this can be resisted and a plural regulatory approach adopted. The ways in which this will occur will need to be worked out on a case-by-case basis depending upon the particular circumstances and opportunities, but can only occur if there is first of all a change of mindset towards an embracing of pluralism and an awareness of the undesirability of the global system's current claims of universality.

The second observation emerging from the investigation of Melanesian intellectual property systems is that the current neoliberal or marketbased focus of the global intellectual property system is a narrow one. Problematically, it largely renders invisible a whole range of factors that have powerful impacts upon both the creation of new intangible resources and their distribution. These include social relationships and cultural and cosmological understandings. A market-based focus can also obscure the fact that there may be values associated with particular intangible resources that are unable to be factored into a purely neoliberal economic framework-for example, values associated with particular aspects of cultural heritage or even genetic resources. One response is to seek to carve out certain areas as being explicitly inalienable and available to all, such as the Italian public cultural public domain (see articles 822.2, 826.2 and 3. of the Italian civil code). An alternative approach is to work towards gradually imbuing intellectual property mechanisms with more non-economic considerations, such as, for example including questions of culture as relevant (or even central) to intellectual property policy design.

\section{References}

Antons, C. (ed.) 2009. Traditional Knowledge, Traditional Cultural Expressions and Intellectual Property Law in the Asia-Pacific Region. The Netherlands: Kluwer Law International.

Astruc, M. 2014. Innovation Occurs in Informal Economy, Needs Policy Framework, Panellists Say. Intellectual Property Watch, 3 June. www.ip-watch. org/2014/06/03/innovation-occurs-in-informal-economy-needs-policyframework-panellists-say/ 
Bainton, N. 2010. The Lihir Destiny: Cultural Responses to Mining in Melanesia. Canberra: ANU E Press. doi.org/10.22459/LD.10.2010

Berman, P. 2012. Global Legal Pluralism: A Jurisprudence of Law beyond Borders. Cambridge University Press. doi.org/10.1017/CBO9781139028615

Bragdon, S. 2013. Small Scale Farmers: The Missing Element in the WIPO-IGC Draft Articles on Genetic Resources. Briefing Paper No. 1. New York: Quaker United Nations Office. www.quno.org/resource/2013/7/small-scale-farmersmissing-element-wipo-igc-draft-articles-genetic-resources

Buse, J. and R. Taringa 1995. Cook Island Maori Dictionary. Cook Islands: Ministry of Education, Government of the Cook Islands and The Australian National University.

Chand, S.S., L.E. Chambers, M. Waiwai, P. Malsale and E. Thompson 2014. Indigenous Knowledge for Environmental Prediction in the Pacific Island Countries. Weather, Climate. and Society 6(4):445-50. doi.org/10.1175/ WCAS-D-13-00053.1

Claudie, D.J., S.J. Semple, N.M. Smith and B.S. Simpson 2012. Ancient but New: Developing Locally Driven Enterprises Based on Traditional Medicines in Kuuku l'yu Northern Homelands, Cape York, Queensland, Australia. In P. Drahos and S. Frankel (eds), Indigenous Peoples' Innovation: Intellectual Property Pathways to Development. Canberra: ANU E Press. doi.org/10.22459/ IPI.08.2012.02

Collier P. 2007. The Bottom Billion: Why the Poorest Countries are Failing and What Can Be Done About It. Oxford: Oxford University Press.

Cornell, D. and N. Muvangua (eds) 2012. uBuntu and the Law: African Ideals and Postapartheid Jurisprudence. New York: Fordham University Press.

Cruikshank, J. 2012. Are Glaciers ‘Good to Think With’? Recognising Indigenous Environmental Knowledge. Anthropological Forum 22(3):239-50. doi.org/ 10.1111/j.1944-8287.2003.tb00221.x

Curry, G. 2003. Moving Beyond Post development: Facilitating Indigenous Alternatives for 'Development'. Economic Geography 79(4):405-23. doi.org/ 10.1111/j.1745-5871.2011.00733.x

Curry, G. and G. Koczberski 2012. Relational Economies, Social Embeddedness and Valuing Labour in Agrarian Change: An Example from the Developing World. Geographical Research 50(4):377-92. 
Dalsgaard, S. 2009. Claiming Culture: New Definitions and Ownership of Cultural Practices in Manus Province, Papua New Guinea. The Asia Pacific Journal of Anthropology 10(1):20-32. doi.org/10.1080/14442210802706889

De Beer, J., K. Fu and S. Wunsch-Vincent 2013. Economic Research Working Paper No. 10: The informal economy, innovation and intellectual propertyConcepts, metrics and policy considerations. Geneva: WIPO. www.wipo.int/ edocs/pubdocs/en/wipo_pub_econstat_wp_10.pdf

de Castro, E.V. 2004. Exchanging Perspectives: The Transformation of Objects into Subjects in Amerindian Ontologies. Common Knowledge 10(3):463-84. doi.org/10.1215/0961754X-10-3-463

de Schutter, O. 2014. Final Report of Special Rapporteur on the Right to Food to the UN Human Rights Council: The Transformative Potential of the Right to Food. www.srfood.org/en/final-report-to-un-human-rights-council

Drahos, P. 2014. Intellectual Property, Indigenous People and their Knowledge. Cambridge: Cambridge University Press. doi.org/10.1017/CBO9781107 295230

Drahos, P. and S. Frankel 2012. Indigenous Peoples' Innovation and Intellectual Property: The Issues. In P. Drahos and S. Frankel (eds), Indigenous Peoples' Innovation: Intellectual Property Pathways to Development. Canberra: ANU E Press. doi.org/10.22459/IPI.08.2012.01

Easterly, W. 2006. The White Man's Burden: Why the West's Efforts to Aid the Rest Have Done So Much Ill and So Little Good. Oxford: Oxford University Press.

Ely, A., A. Smith, A. Stirling, M. Leach and I. Scoones 2013. Innovation Politics Post-Rio 20+: Hybrid Pathways to Sustainability? Environment and Planning C: Government and Policy 31. doi.org/10.1068/c12285j

Engle Merry, S. 1991. Law and Colonialism. Law \& Society Review 25:889-922. doi.org/10.2307/3053874

Escobar, A. 1995. Encountering Development. The Making and Unmaking of the Third World. Princeton: Princeton University Press.

Escobar, A. 2010. Latin America at a Crossroads. Cultural Studies 24(1):1-65. doi.org/10.1080/09502380903424208

Filer, C. and M. Macintyre 2006. Grass Roots and Deep Holes: Community Responses to Mining in Melanesia. Contemporary Pacific 18(2):215-31. doi.org/10.1353/cp.2006.0012 
Finger, J.M. and P. Schuler 2003. Poor People's Knowledge: Promoting Intellectual Property in Developing Countries. Washington, DC: World Bank.

Fitzpatrick, D., A. McWilliam and S. Barnes 2012. Property and Social Resilience in Times of Conflict: Land, Custom and Law in East Timor. Farnham, UK: Ashgate.

Forsyth, M. 2011. The Traditional Knowledge Movement in the Pacific Island Countries: The Challenges of Localism. Prometheus 29(3): 269-86. doi.org/ 10.1080/08109028.2011.629869

Forsyth, M. 2012. Lifting the Lid on 'The Community': Who Has the Right to Control Access to Traditional Knowledge and Expressions of Culture? International Journal of Cultural Property 19:1-31. doi.org/10.1017/S09407 39112000021

Forsyth, M. 2013a. How Can Traditional Knowledge Best be Regulated? Comparing a Proprietary Rights Approach with a Regulatory Toolbox Approach. The Contemporary Pacific 25(1):1-31. doi.org/10.1353/cp.2013. 0004

Forsyth, M. 2013b. How Can the Theory of Legal Pluralism Assist the Traditional Knowledge Debate? Intersections: Gender and Sexuality in Asia and the Pacific 33(December). intersections.anu.edu.au/issue33/forsyth.htm

Forsyth, M. and S. Farran 2015. Weaving Intellectual Property Policy in Pacific Island Countries. Cambridge: Intersentia.

Gegeo, D. and K. Watson-Gegeo 2001. How We Know: Kwara'ae Rural Villagers Doing Indigenous Epistemology. The Contemporary Pacific 31(1):55-88.

Geismar, H. 2013. Treasured Possessions: Indigenous Interventions into Cultural and Intellectual Property. Durham: Duke University Press. doi.org/10.1215/ 9780822399704

Gibson-Graham, J.K. 1996. The End of Capitalism (As We Knew It). Minnesota: University of Minnesota Press.

Gibson-Graham, J.K. 2006. A Postcapitalist Politics. Minnesota: University of Minnesota Press.

Government of Vanuatu 2013. Nikoletan Chiefs Declaration on Climate Change in Vanuatu. Press release, 17 December. Vanuatu: National Advisory Board on Climate Change and Disaster Risk Reduction.

Griffiths, J. 1986. What is Legal Pluralism? Journal of Legal Pluralism 18(24): 1-55. doi.org/10.1080/07329113.1986.10756387 
Griffiths, T. 1993. Indigenous Knowledge and Intellectual Property: A Preliminary Review of the Anthropological Literature. Report prepared for the Foundation of Ethnobiology at the University of Oxford (copy on file with author).

Hirsch, E. and M. Strathern (eds) 2005. Transactions and Creations: Property Debates and the Stimulus of Melanesia. New York: Berghahn Books.

Jansen, T. 2002. Hidden Taro, Hidden Talents: A Study of On-farm Conservation of colocasia esculenta (taro) in Solomon Islands. Solomon Islands Planting Material Network and Kastom Gaden Association. Formerly available at issuu.com/terracircle (site discontinued).

Jolly, M. 2014. Futures, Past or Foregone? Horizons and Rifts in Conversations about Climate Change in Oceania. Paper for Workshop on Pacific Futures: Past and Present. University of Otago, Dunedin, 18-21 June.

Kalinoe, L. and J. Leach (eds) 2004. Rationales of Ownership: Transactions and Claims to Ownership in Contemporary Papua New Guinea. Wantage: Sean Kingston Publishing.

Kariyawasam, K. 2008. Protecting Biodiversity, Traditional Knowledge and Intellectual Property in the Pacific: Issues and Challenges. Asia Pacific Law Review 16(1):73-89. doi.org/10.1080/10192557.2008.11788179

Lai, J. 2013. Maori Traditional Knowledge and New Zealand Patent Law: The 2013 Act and the Dawn of a New Era? atrip.org/wp-content/uploads/2016/ 12/2013-2Jessica-Lai.pdf

Leach J. 2005. Modes of Creativity and the Register of Ownership. In R. Ghosh (ed.), CODE: Collaborative Ownership and the Digital Economy. Cambridge MA: Massachusetts Institute of Technology Press.

Leach, J. 2012. Leaving the Magic Out: Knowledge and Effect in Different Places. Anthropological Forum 22(3):251-70, 258.

Leach, J. and R. Davis 2012. Recognising and Translating Knowledge: Navigating the Political, Epistemological, Legal and Ontological. Anthropological Forum 22(3). doi.org/10.1080/00664677.2012.724007

Lin, W.-y. and J. Law 2013. A Correlative STS? Lessons from a Chinese Medical Practice. CRESC Working Paper Series, Working Paper No. 128. hummedia. manchester.ac.uk/institutes/cresc/workingpapers/wp128.pdf

Lindstrom, L. 1990. Big Men As Ancestors: Inspiration and Copyrights on Tanna (Vanuatu). Ethnology 29:313-26. doi.org/10.2307/3773601 
Lindstrom, L. n.d. A Genealogy of Creativity. Unpublished paper (copy on file with author).

Narsey Lal, P., J. Kinch and F. Wickham 2009. Review of Livelihood Impact, Assessments of, and Adaptation to, Climate Change in Melanesia. Secretariat of the Pacific Regional Environment Programme.

McNamara, K.E. and S.S. Prasad 2013. Valuing Indigenous Knowledge for Climate Change Adaptation Planning in Fiji and Vanuatu. Guest Article for UNU-IAS Traditional Knowledge Initiative. www.unutki.org/news.php? news_id=1 82\&doc_id=39 (site discontinued).

Pahuja, S. 2011. Decolonising International Law: Development, Economic Growth and the Politics of Universality. Cambridge: Cambridge University Press. doi.org/10.1017/CBO9781139048200

Peteru, C. 2008. Access and Benefit Sharing issues in the Pacific: The Fable of the Mamala Tree. Presentation. gfbr9.hrc.govt.nz/presentations/Clark\%20Peteru. doc (site discontinued).

Piketty, T. 2014. Capital in the Twenty-First Century. Boston: Harvard University Press. doi.org/10.4159/9780674369542

Platteau, J.P. 1996. The Evolutionary Theory of Land Rights as Applied to SubSaharan Africa: A Critical Assessment. Development and Change 27(1):29-86. doi.org/10.1111/j.1467-7660.1996.tb00578.x

Platteau, J.P. 2000. Does Africa Need Land Reform? In C. Toulmin and J. Quan (eds), Evolving Land Rights, Policy and Tenure in Africa. London: DFID Issues Series, IIED and Natural Resources Institute, 51-74.

Porter, D. 2012. Some Implications of the Application of Legal Pluralism to Development Practice. In B. Tamanaha, C. Sage and M. Woolcock (eds), Legal Pluralism and Development: Scholars and Practitioners in Dialogue. Cambridge: Cambridge University Press, 162-76. doi.org/10.1017/CBO 9781139094597.014

Quijano, A. 2007. Coloniality and Modernity/Rationality. Cultural Studies 21(2-3):177.

Regan, A. 1998. Causes and Course of the Bougainville Conflict. Journal of Pacific History 33(3):269-85. doi.org/10.1080/00223349808572878

Robinson, D. 2008. Beyond 'Protection': Promoting Traditional Knowledge Systems in Thailand. In J. Gibson (ed.), Patenting Lives: Development and Culture. London: Routledge, 121-38. 
Simet, J. 2000. Copyrighting Traditional Tolai Knowledge? In K. Whimp and M. Busse (eds), Protection of Intellectual, Biological and Cultural Property in Papua New Guinea. Canberra: Asia-Pacific Press, 62-80.

Smith, L.T. 1999. Decolonizing Methodologies: Research and Indigenous Peoples. London: St Martin's Press.

Stern, M. 2013. Music in Traditional Exchanges in North Vanuatu. Pacific Studies 36(1-2): 59-76.

Sunder, M. 2007. The Invention of Traditional Knowledge. Law and Contemporary Problems 70:97-124.

Tobin, B.M. 2013. Bridging the Nagoya Compliance Gap: The Fundamental Role of Customary Law in Protection of Indigenous Peoples' Resource and Knowledge Rights. Law, Environment and Development Journal 9(2):142-62. www.lead-journal.org/content/13142.pdf

Twining, W. 2009. General Jurisprudence: Understanding Law from a Global Perspective. Cambridge: Cambridge University Press.

UNCTAD 2013. Trade and Environment Review 2013: Wake Up Before It Is Too Late. unctad.or g/en/PublicationsLibrary/ditcted2012d3_en.pdf

UNESCO Office for the Pacific States 2013. Traditional Knowledge for Adapting to Climate Change: Safeguarding Intangible Cultural Heritage in the Pacific. Apia, Samoa and Republic of Korea. unesdoc.unesco.org/ images/0022/002253/225313E.pdf

Urwin Consulting 2003. Consultancy for the Capacity Needs Assessment on Access and Benefit Sharing and the Protection of Traditional Knowledge, Practices and Innovations: Final report. www.mnre.gov.ws/documents/reports/ CapacityNeedsAssessmentABSandTKJune2003.pdf (site discontinued).

Vaioleti, T.M. 2006. Talanoa Research Methodologies: A Developing Position on Pacific Research. Waikato Journal of Education (12):12, 21-34.

Vanuatu Cultural Centre 2010. The National Action Plan for the Safeguarding of Sand Drawing, a UNESCO Masterpiece of the Oral and Intangible Heritage of Humanity. archive.is/PwCLj

Vermeylen, S. 2010. Law as a Narrative: Legal Pluralism and Resisting EuroAmerican (Intellectual) Property Law Through Stories. Journal of Legal Pluralism 61:53-78. doi.org/10.1080/07329113.2010.10756642 
Vermeylen, S. 2013. The Nagoya Protocol and Customary Law: The Paradox of Narratives in the Law. Law, Environment and Development Journal 9(2): 187-201.

Vierros, M., A. Tawake, F. Hickey, A. Tiraa and R. Noa 2010. Traditional Marine Management Areas of the Pacific in the Context of National and International Law and Policy. Darwin: United Nations University-Traditional Knowledge Initiative. archive.ias.unu.edu/resource_centre/Traditional_ Marine_Management_Areas_Sept_2010_single_page_webversion_v2.pdf

von Benda-Beckmann, F. 1985. Some Comparative Generalizations about the Differential Use of State and Folk Institutions of Dispute Settlement. In A. Allott and G.R. Woodman (eds), People's Law and State Law: The Bellagio Papers. The Netherlands: Foris Publications. doi.org/10.1515/ 9783110866285.187

Walsh, C. 2009. The Plurinational and Intercultural State: Decolonization and State Re-founding in Ecuador. Kult—Special Issue 6. Epistemologies of Transformation: The Latin American Decolonial Option and its Ramifications. Postkolonial.dk/artikler/kult_6/WALSH.pdf

World Intellectual Property Organization (WIPO) 2013. Intellectual Property, Traditional Knowledge and Traditional Cultural Expressions/Folklore: A Guide for Countries in Transition. Geneva.

Ziervogel, G. and A. Opere (eds) 2010. Integrating Meteorological and Indigenous Knowledge-Based Seasonal Climate Forecasts in the Agricultural Sector. Climate Change Adaptation in Africa learning paper series. International Development Research Centre, Ottawa, Canada. 
This text is taken from Understanding Oceania: Celebrating the University of the South Pacific and its collaboration with The Australian National University, edited by Stewart Firth and Vijay Naidu, published 2019 by ANU Press, The Australian National University, Canberra, Australia.

doi.org/10.22459/UO.2019.06 